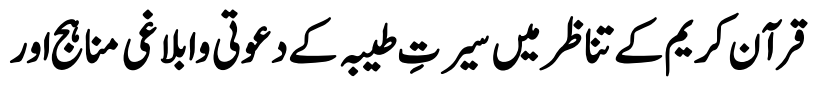 عمرافريّاسكم متنيت
}

\section{The Scientific Analysis and Study of Methods of the Prophetic Preaching in Context of the Holy Quran}

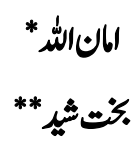

\begin{abstract}
The main feature and distinction of Prophet Muhammad SAWS, Prophethood is his preaching the humanity and invitation towards the religion of Islam. Allah sent him as the last of his prophets. His preaching of the religion is an eternal argument which shows that the message of the Prophet is the last, his prophecy is the last and that the religion Islam is the eternal rule for mankind.

The principles and methods of preaching adopted by the Holy Prophet SAWS are studied here in this research "The Scientific Analysis and Research of Prophetic preaching methods in context of the Holy Quran".

The research shows that these principles and methods of preaching are the eternal source of guidance for all of the human beings. These are the methods by which we can preach and spread the religion, Islam throughout the world.
\end{abstract}

Key Words: distinction, Prophethood, eternal argument, guidance.

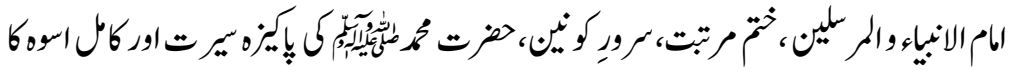

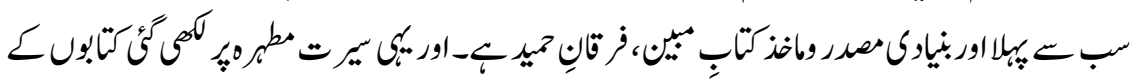

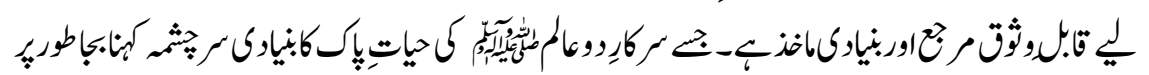

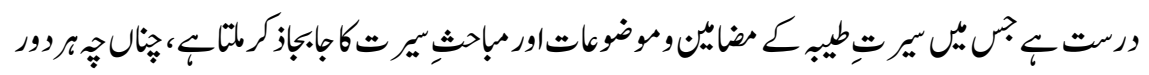

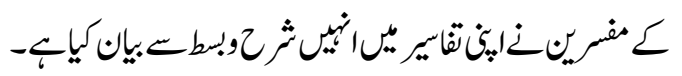

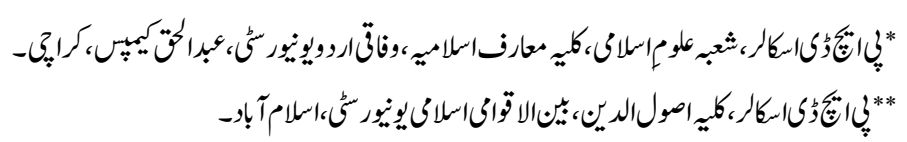




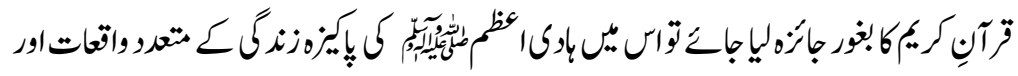

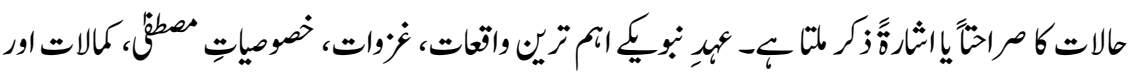

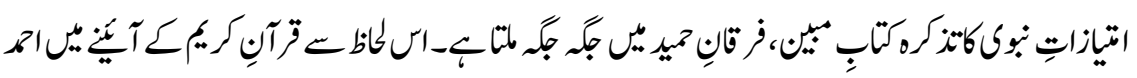

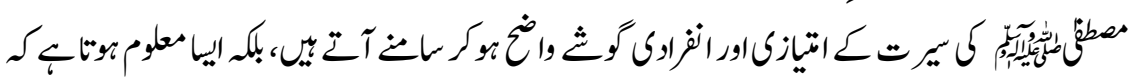

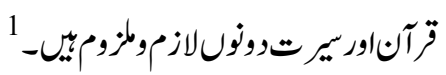

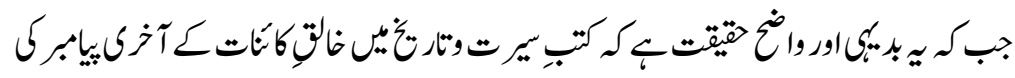

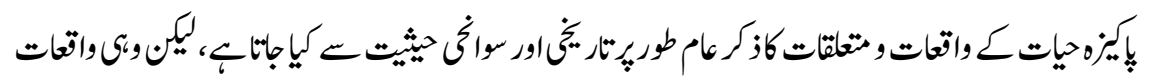

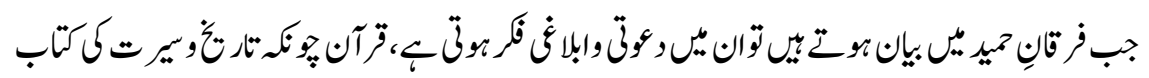

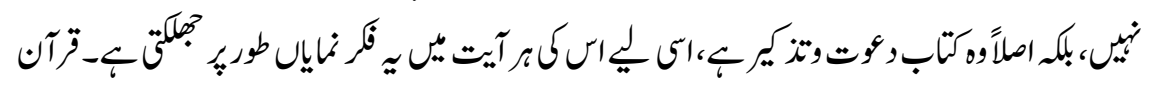

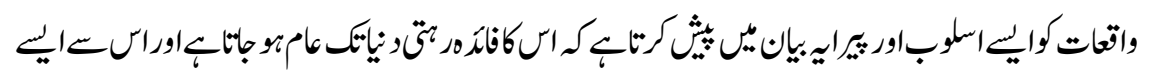

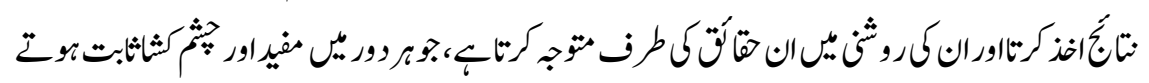

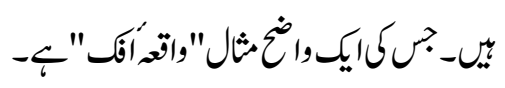

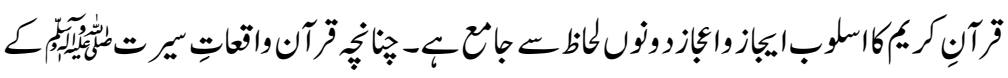

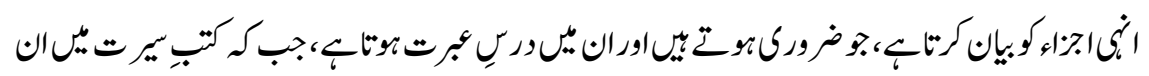

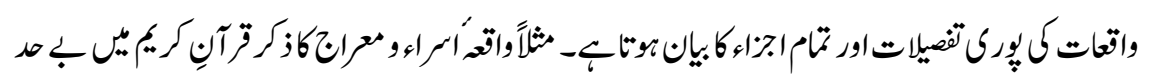

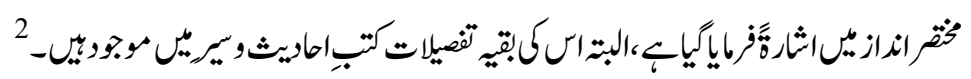

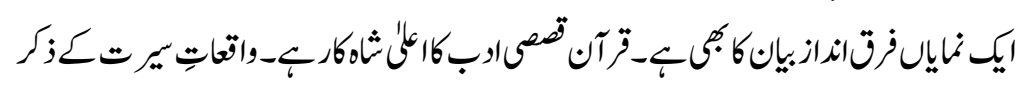

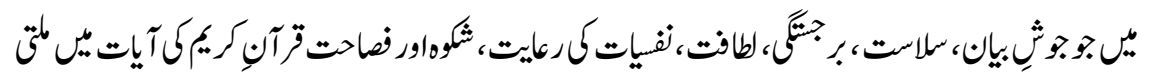

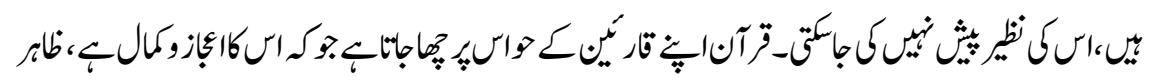

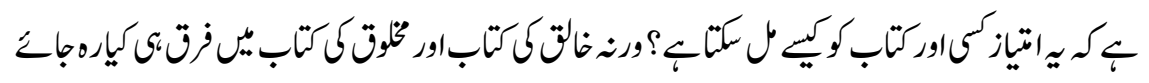

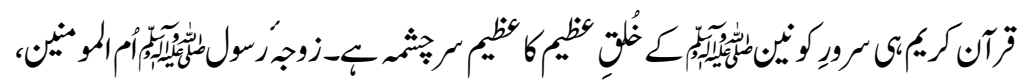

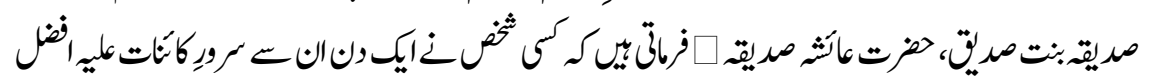

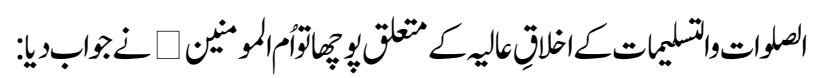




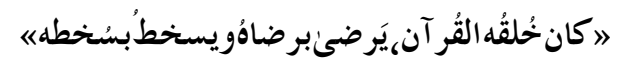

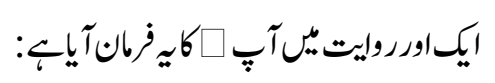

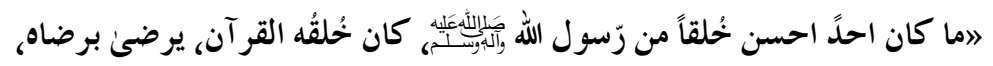

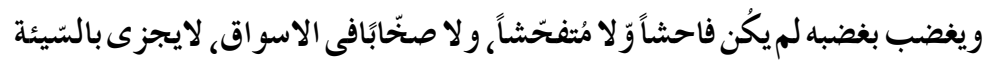

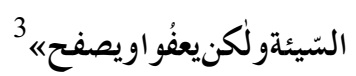

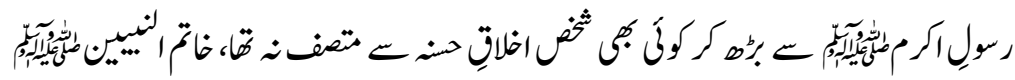

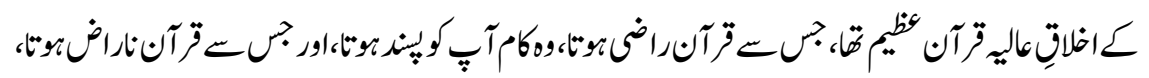

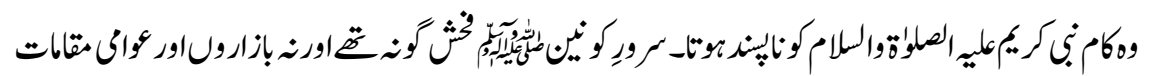

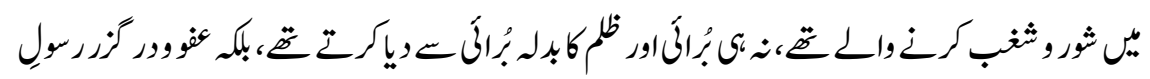

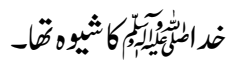

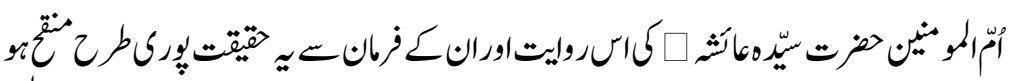

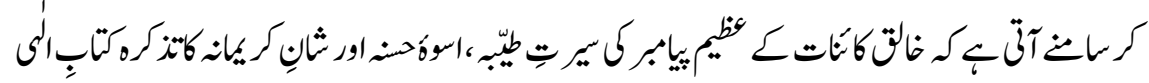

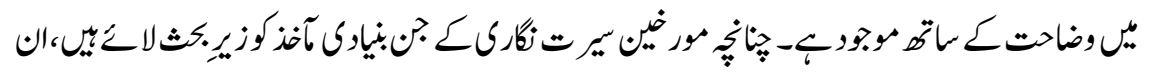

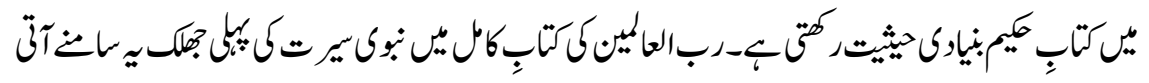

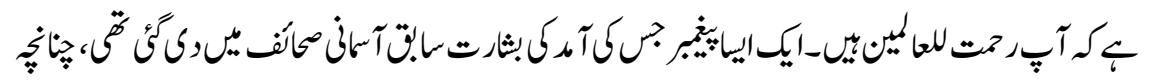

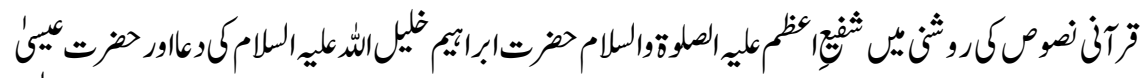

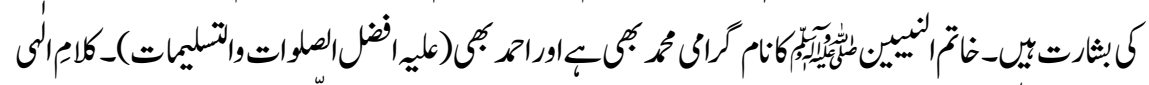

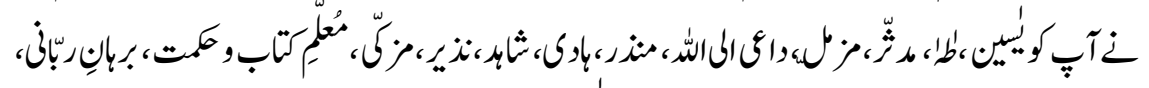

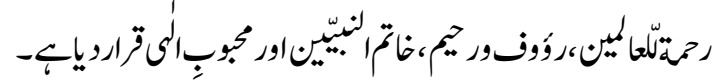

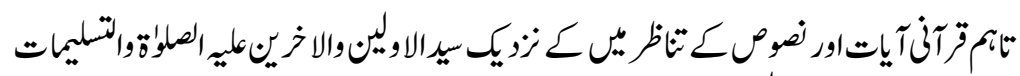

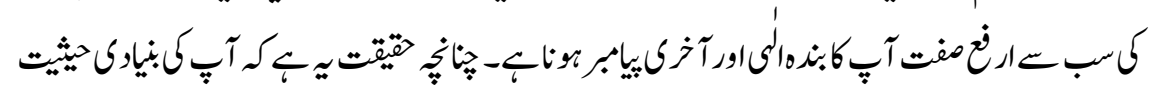

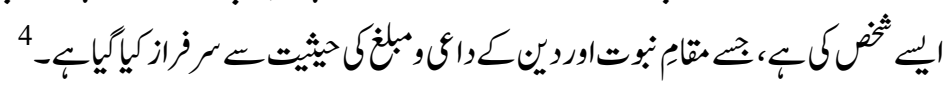




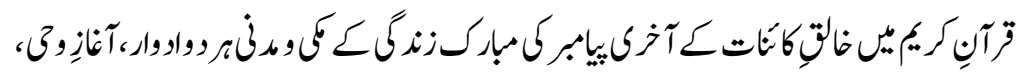

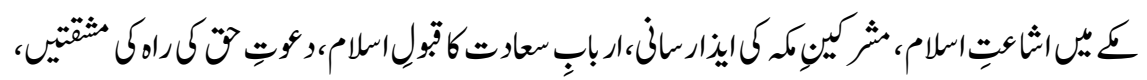

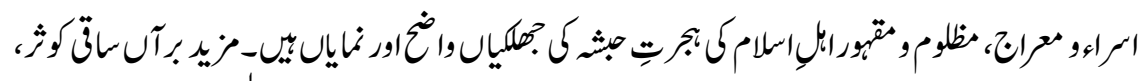

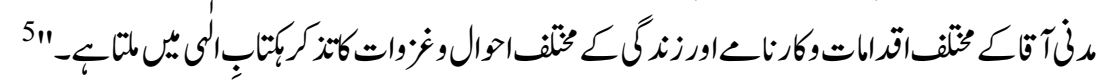

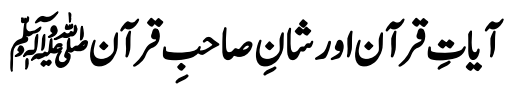

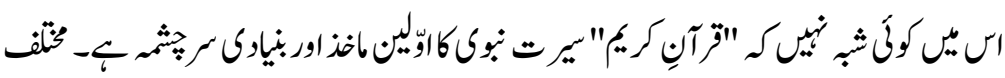

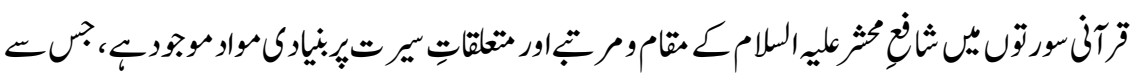

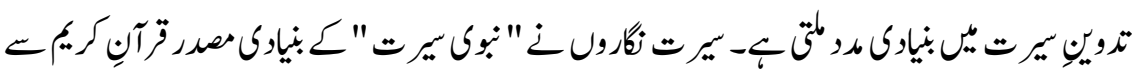

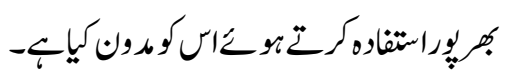

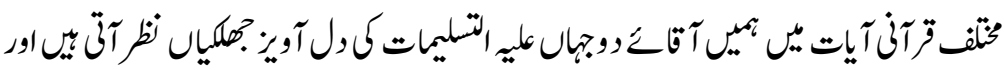

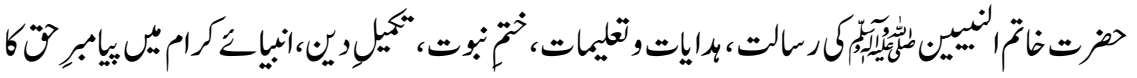

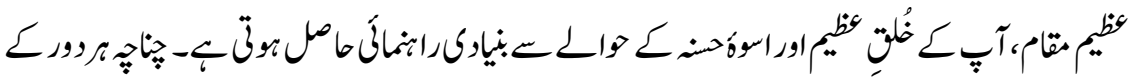

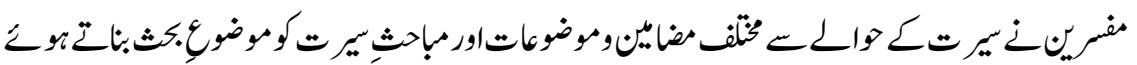

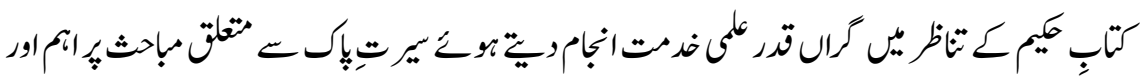

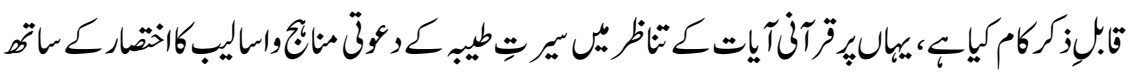

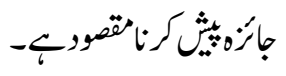

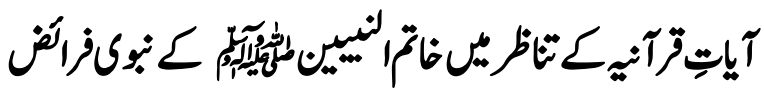

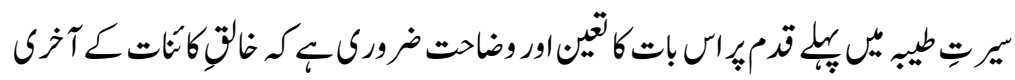

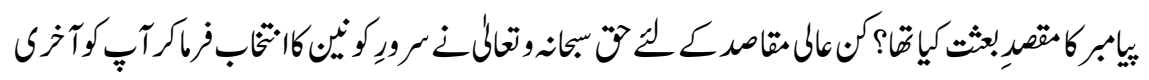

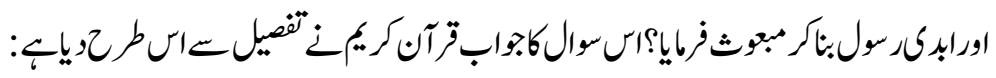

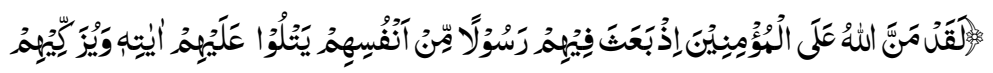

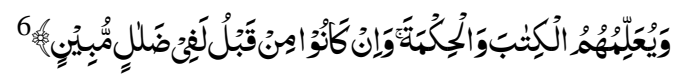




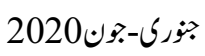

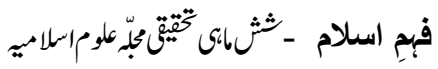

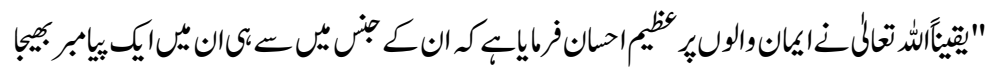

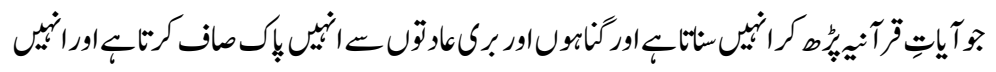

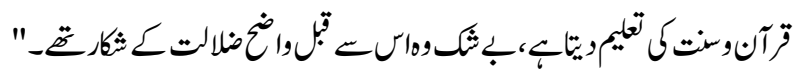

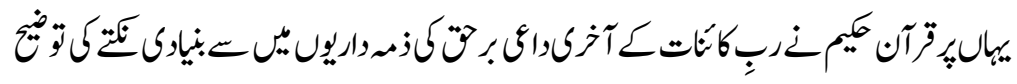

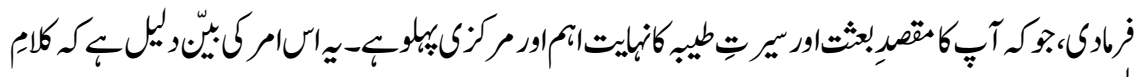

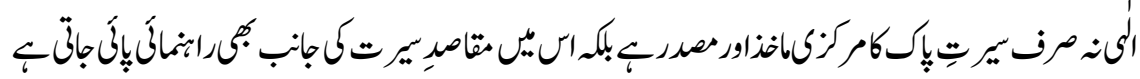

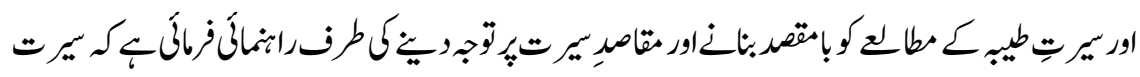

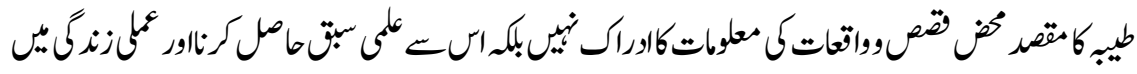

اسناطاطلاقن

فاقام لميلين

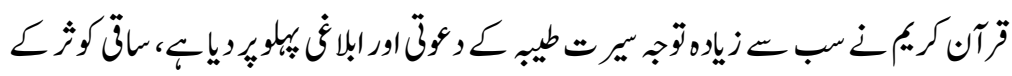

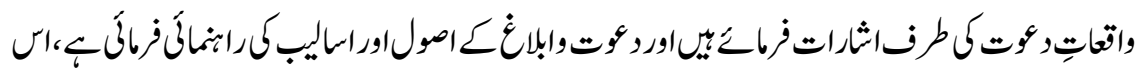

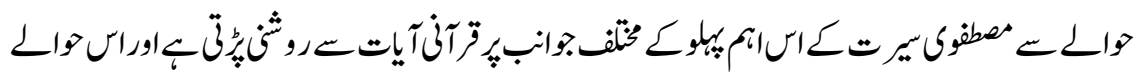

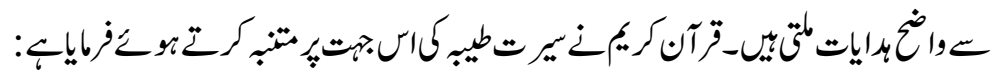

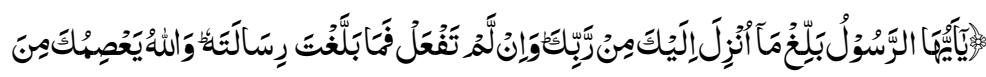

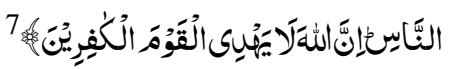

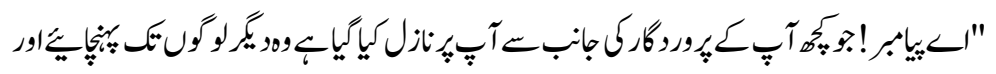

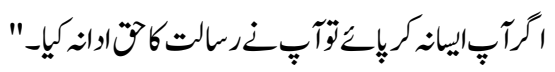

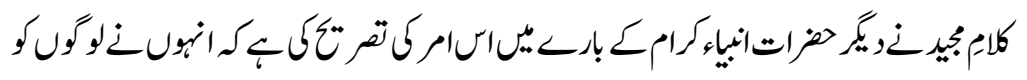

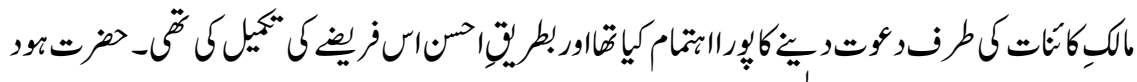

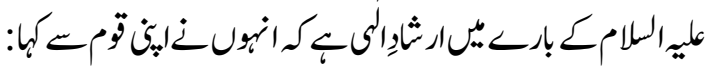

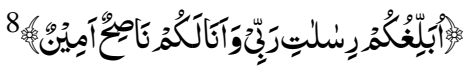

91 


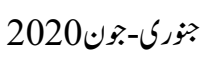

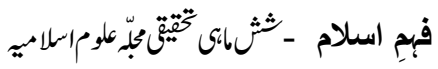

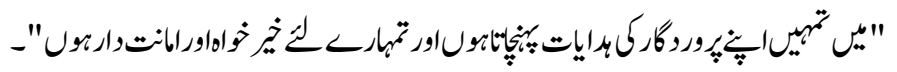

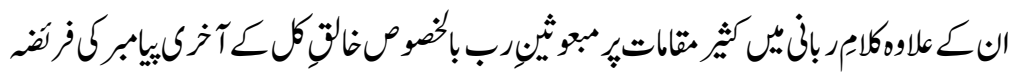

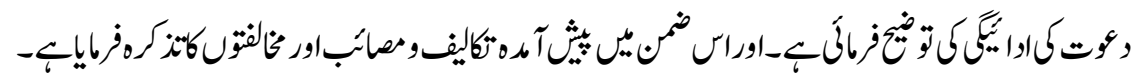

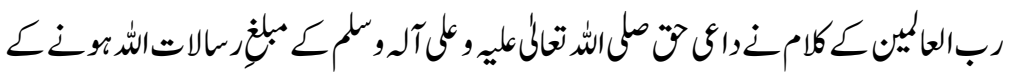

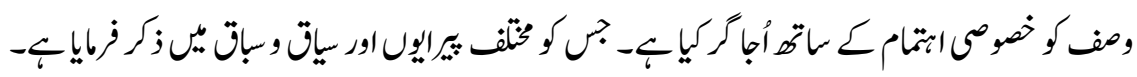

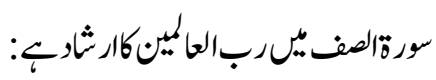
9

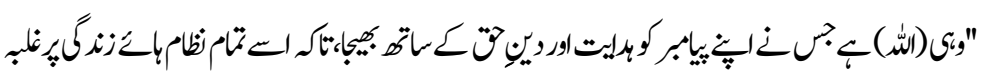

,

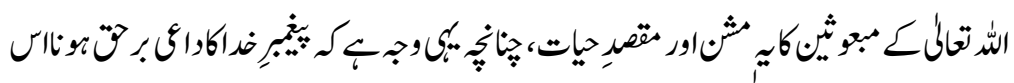

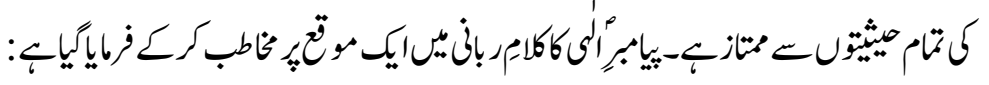

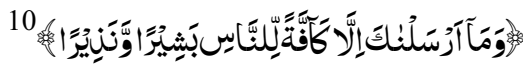

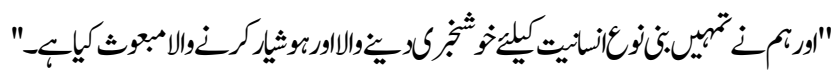

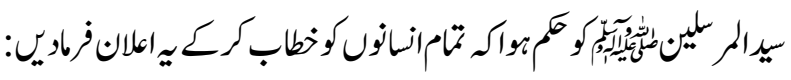

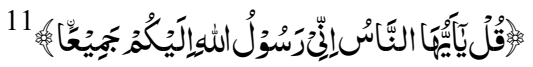

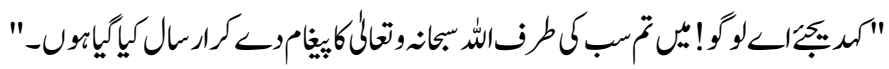

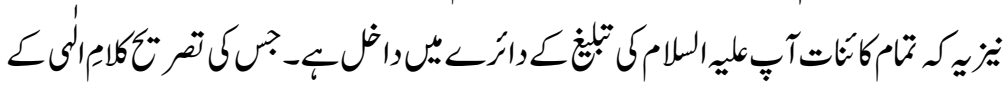

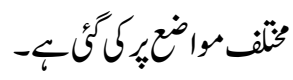

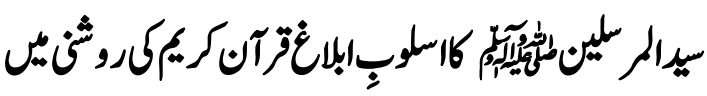

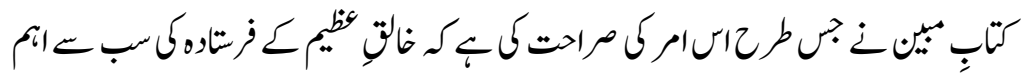

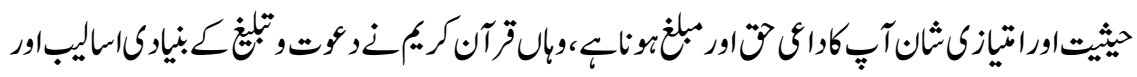

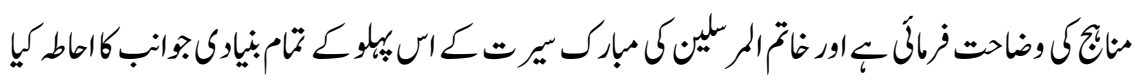

92 


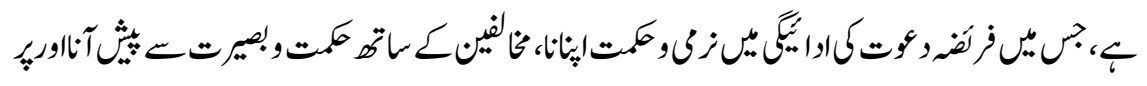

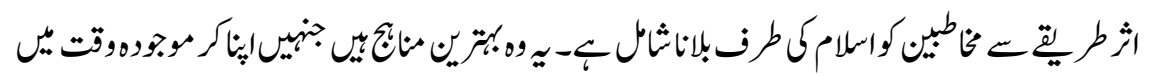

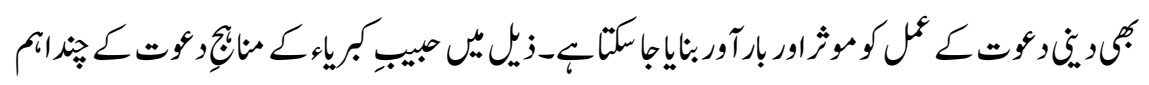

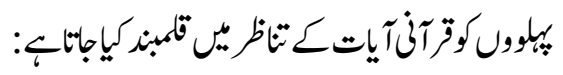

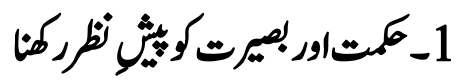

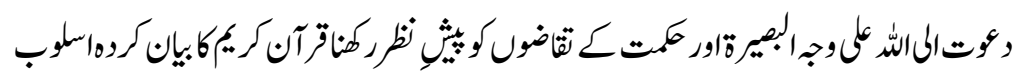

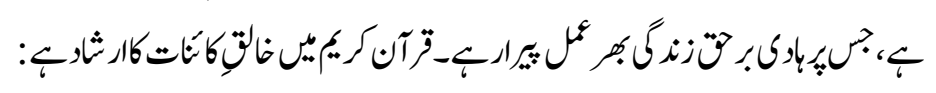
12 بان

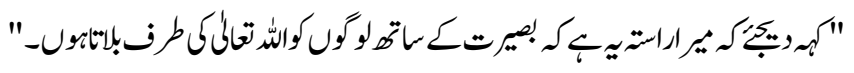

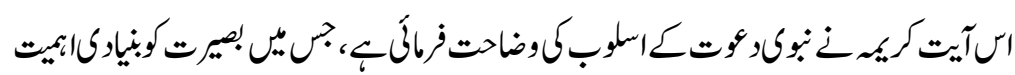

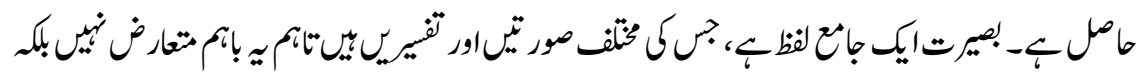

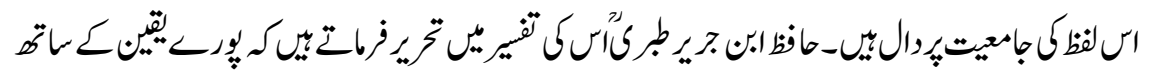

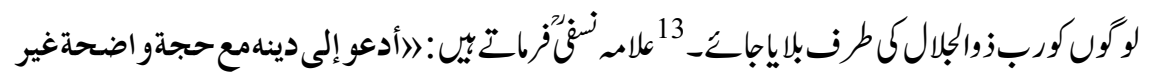
عمياء《ر 14

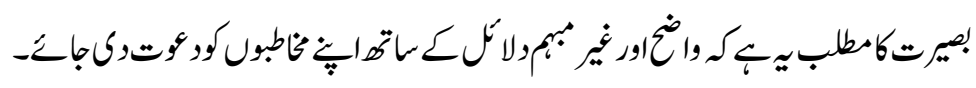

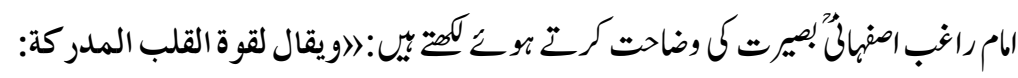

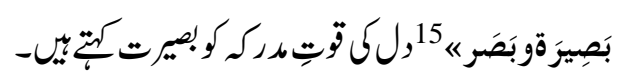

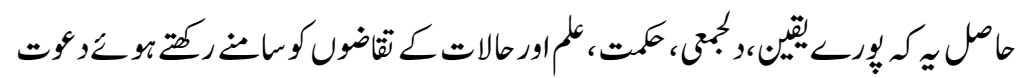

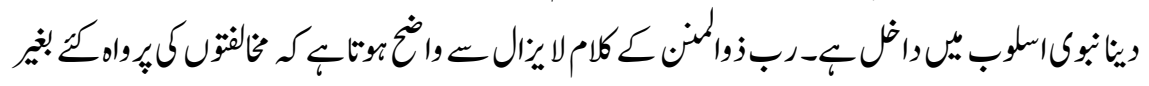

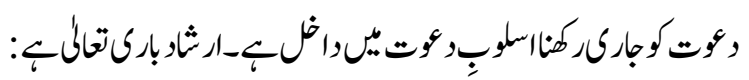

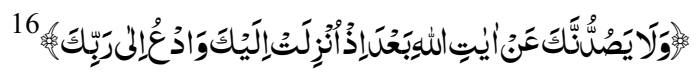




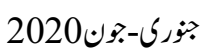

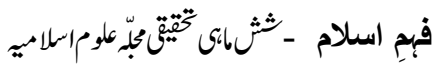

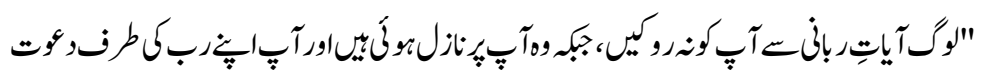

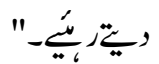

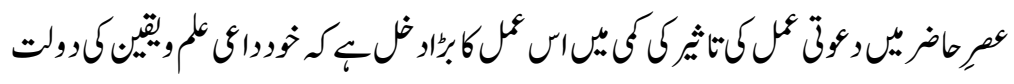

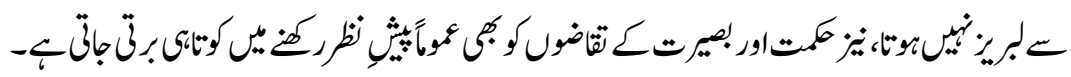

2_اظاص 20لمبتاوردلهوزى

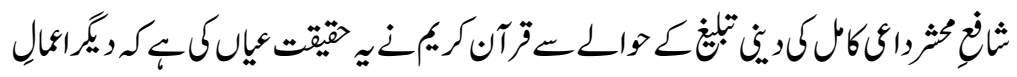

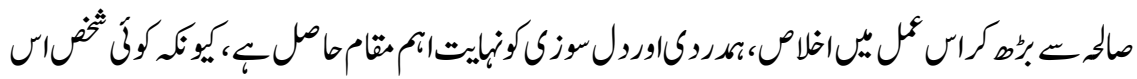

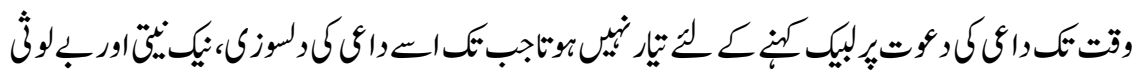

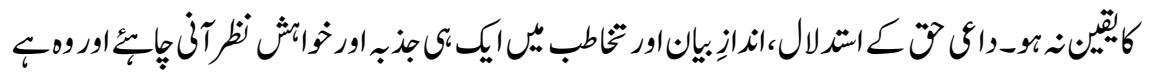

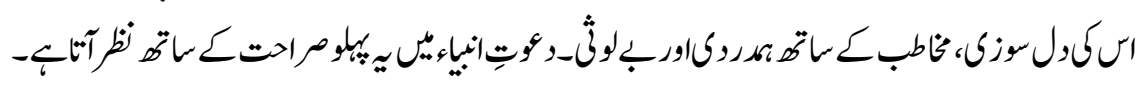

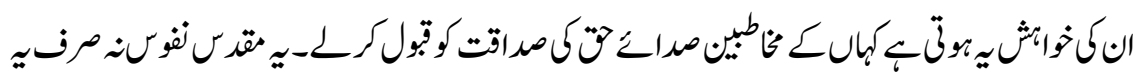

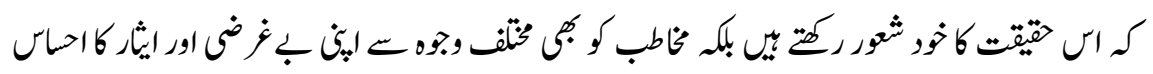

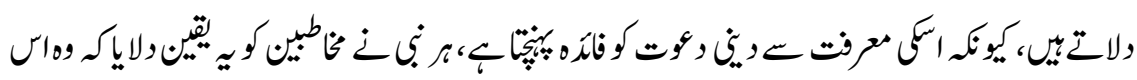

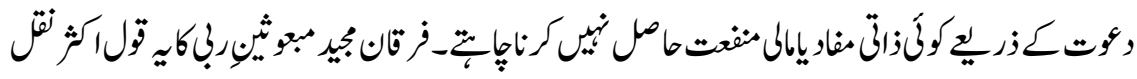

كر

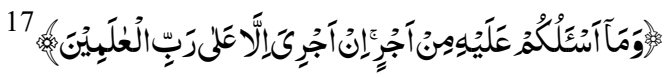

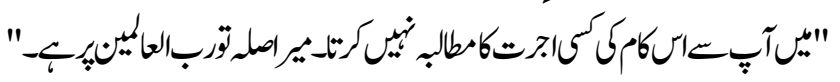

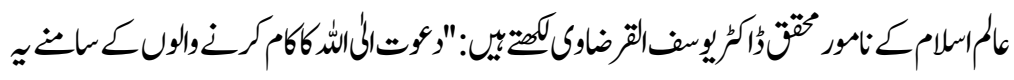

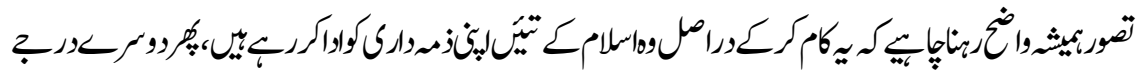

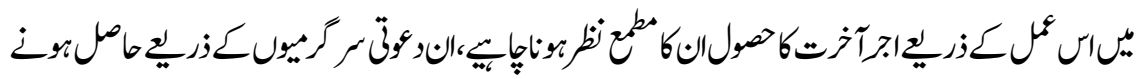

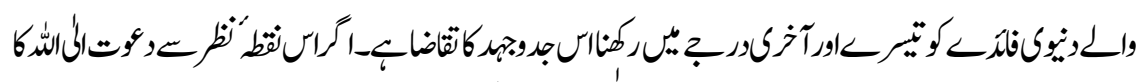

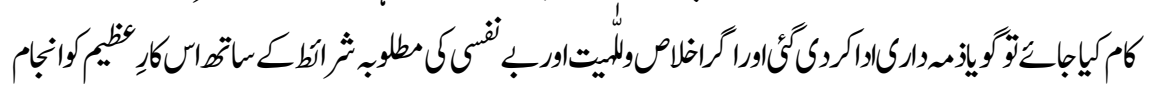

94 


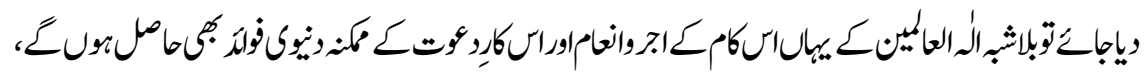

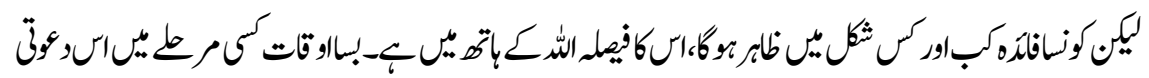

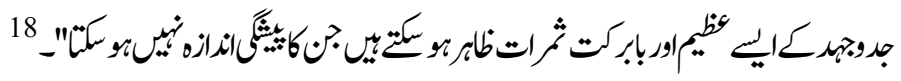

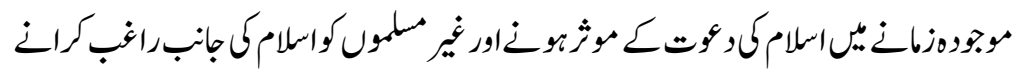

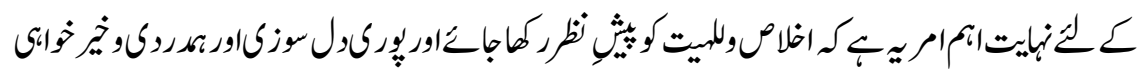

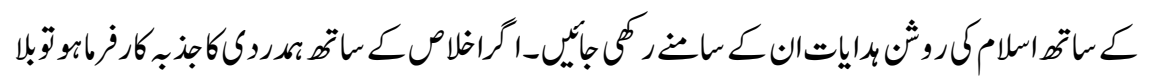

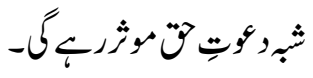

\section{3-جرواكراهـاجتناب}

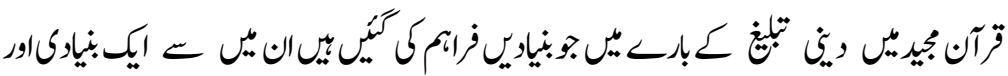

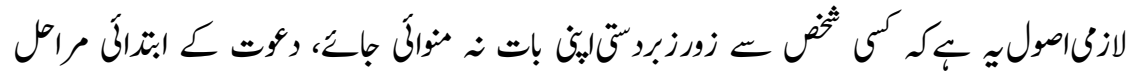

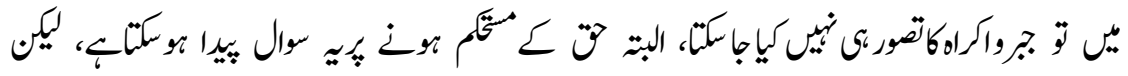

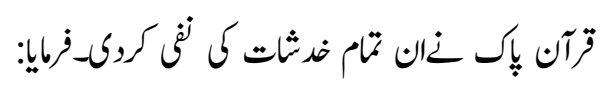
界

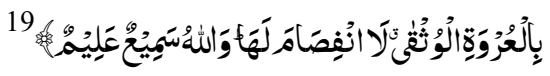

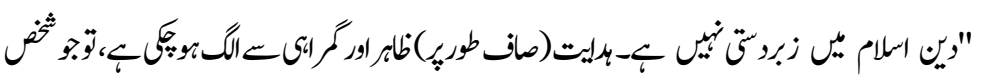

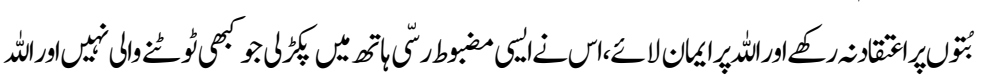

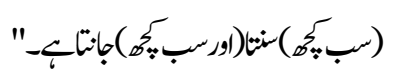

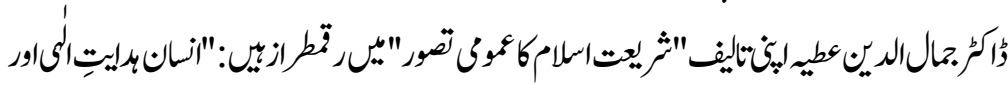

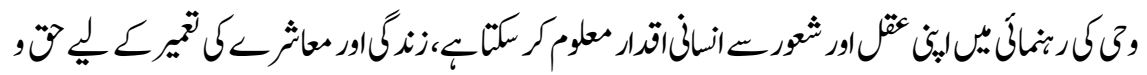

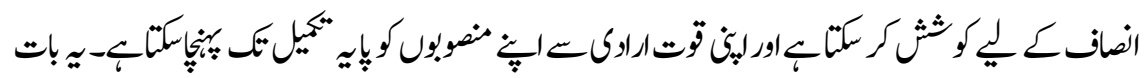

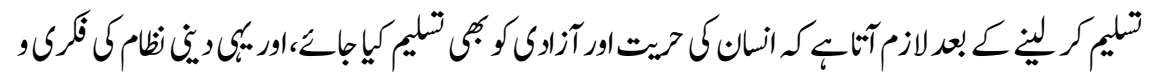

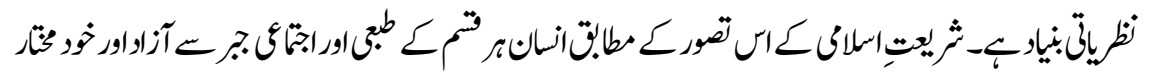

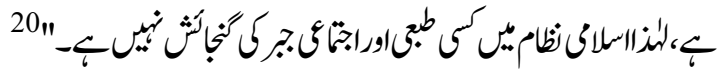




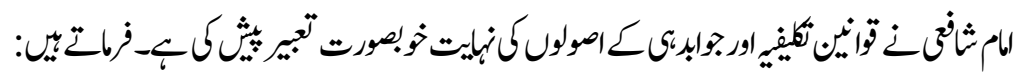

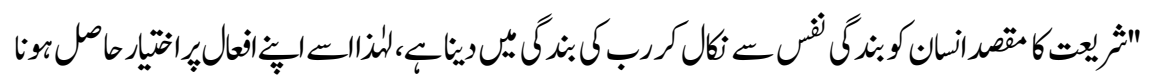

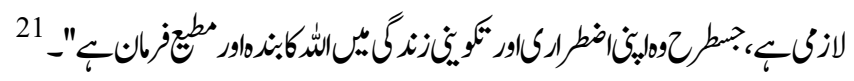

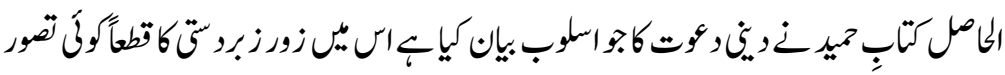

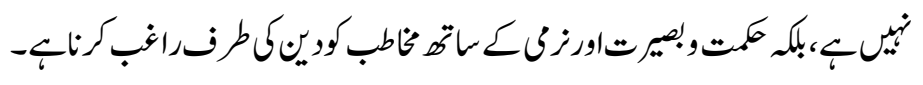

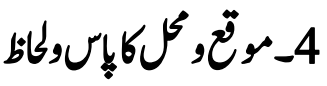

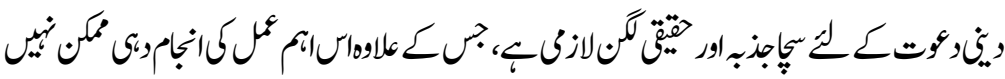

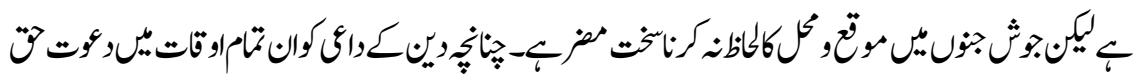

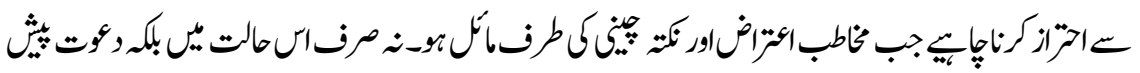

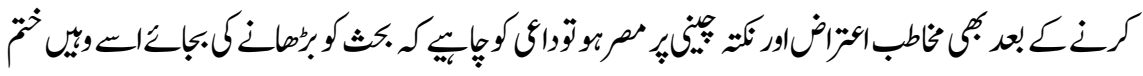

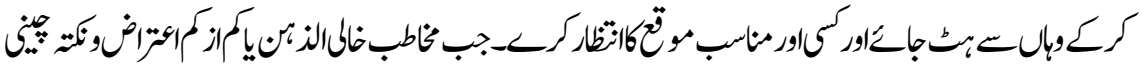

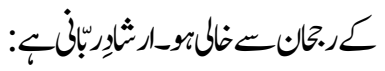

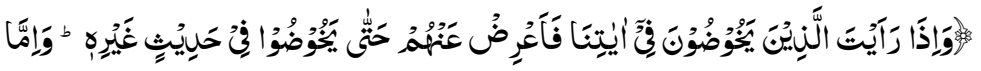

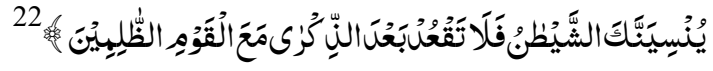

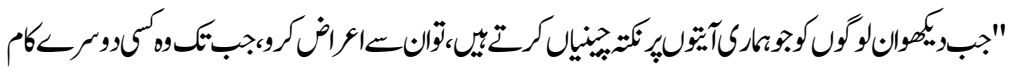

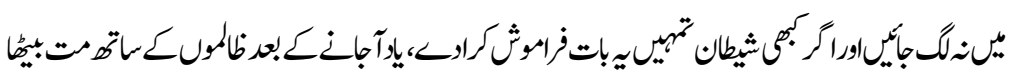
كرو."

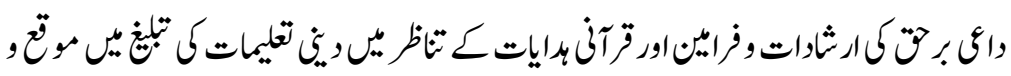

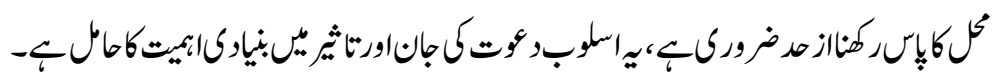

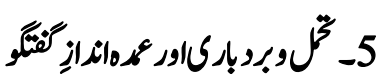

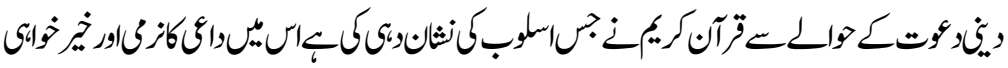

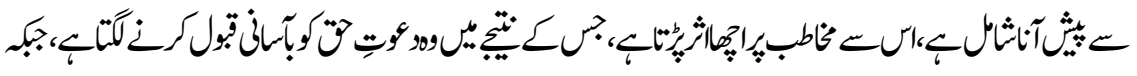




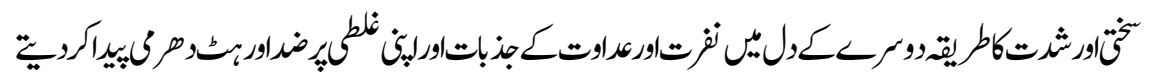

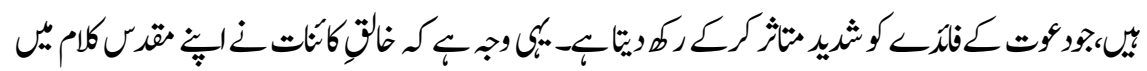

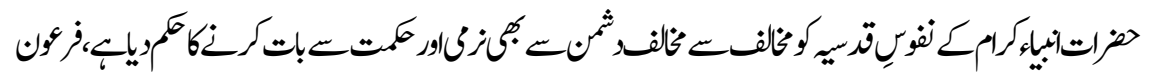

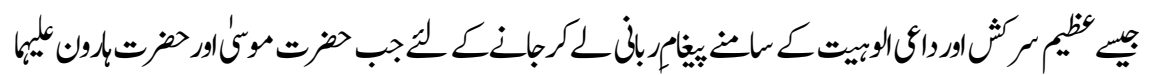

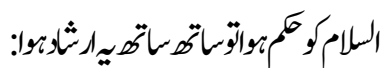

23 23

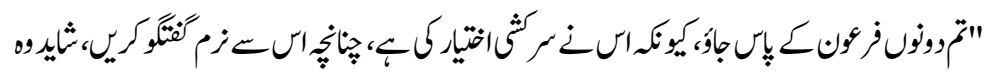

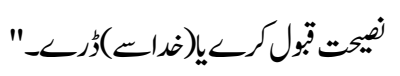

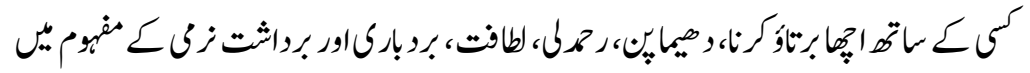

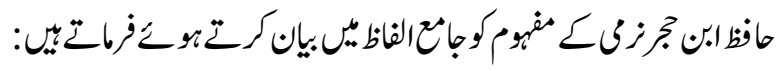

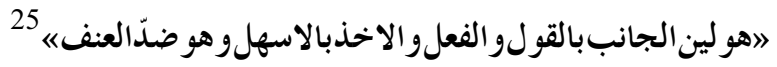

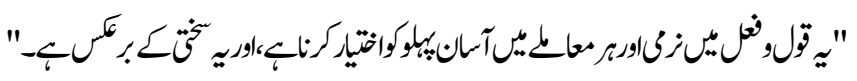

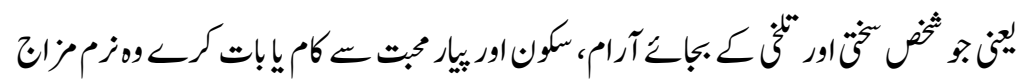

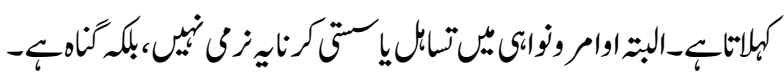

\section{6ـموعظدحسن:نوكو ؤتكاموثزاسلوب}

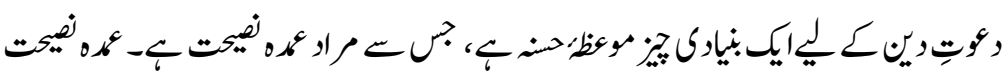

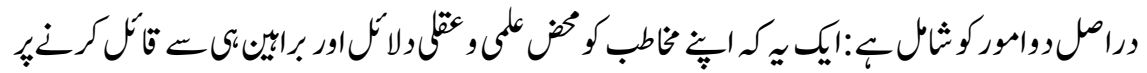

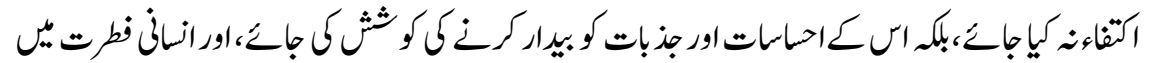

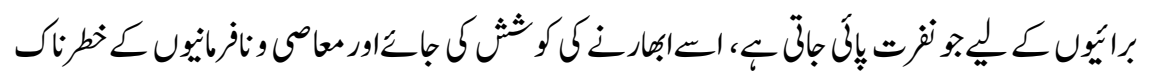

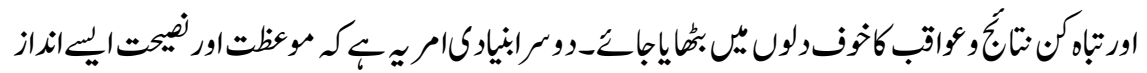

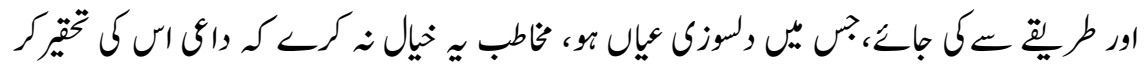




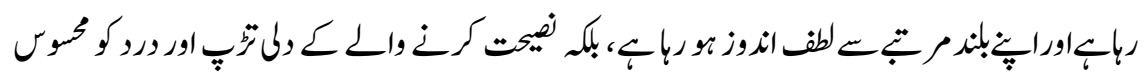

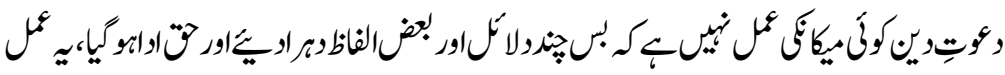

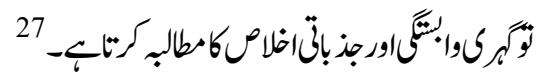

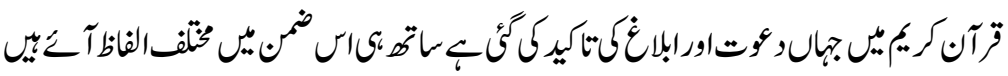

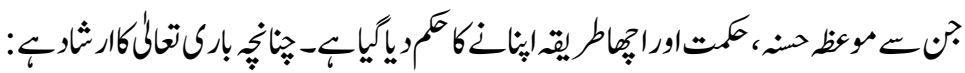

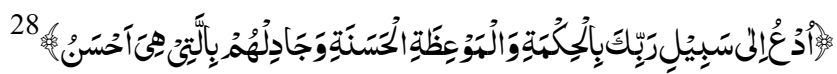

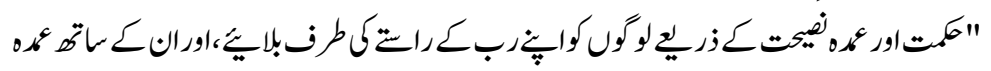

$$
\begin{aligned}
& \text { اوراحتر ليق س.كث كري-" }
\end{aligned}
$$

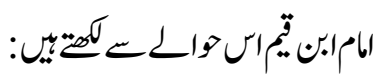

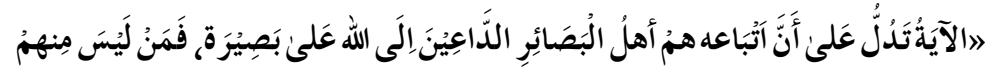

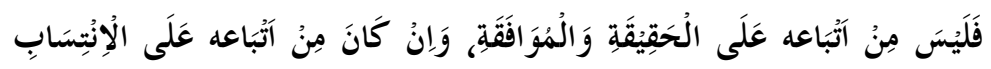

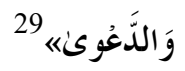

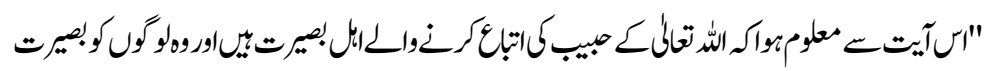

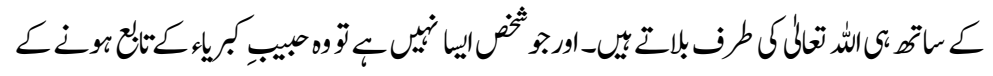

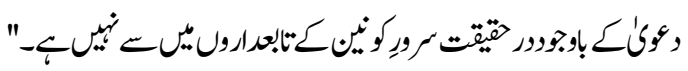

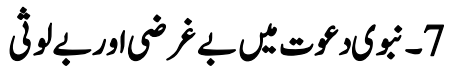

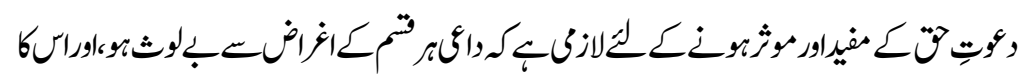

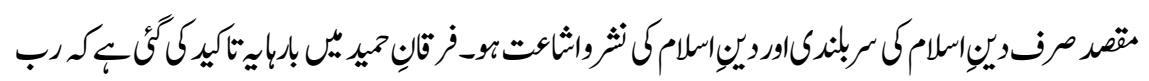

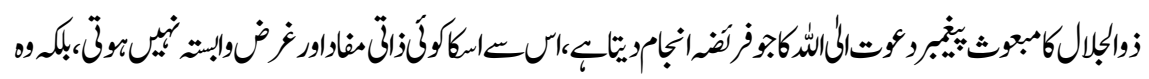

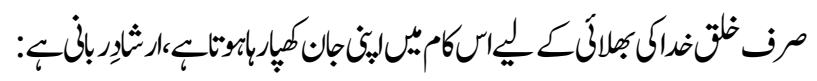

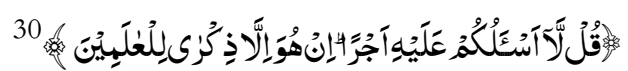

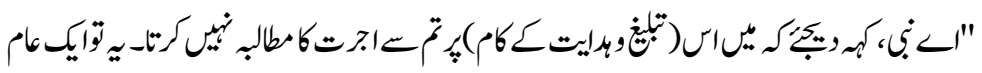

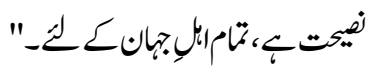




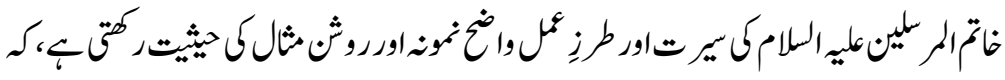

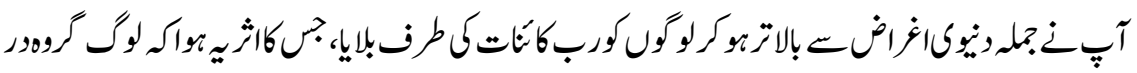

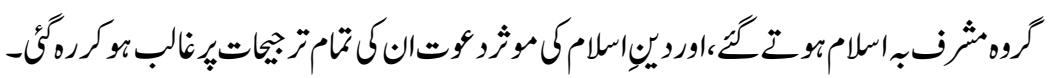

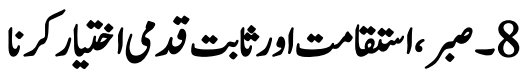

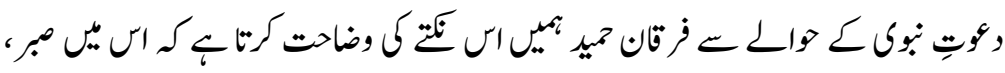

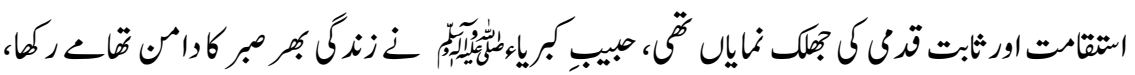

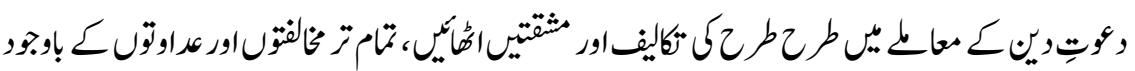

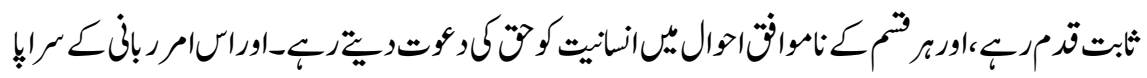

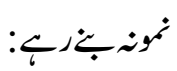

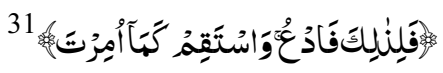

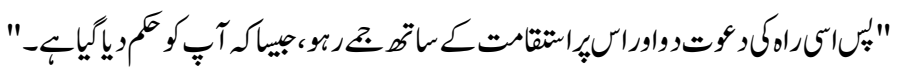

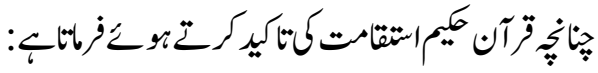

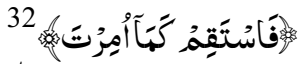

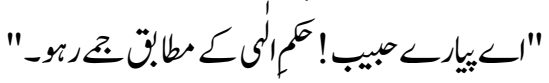

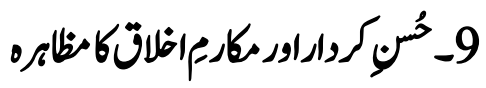

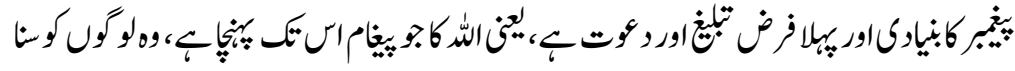

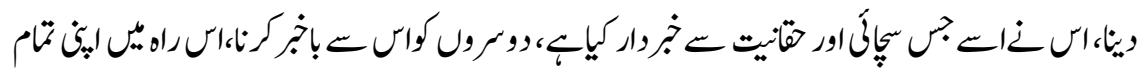

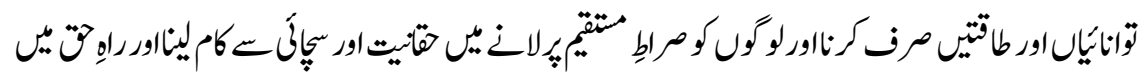

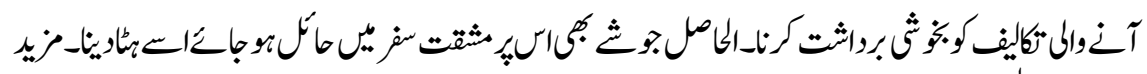

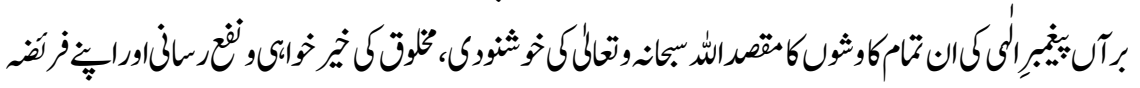

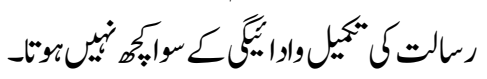




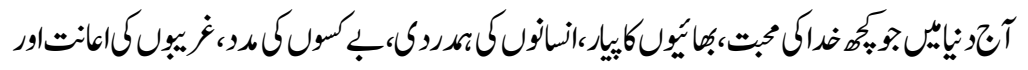

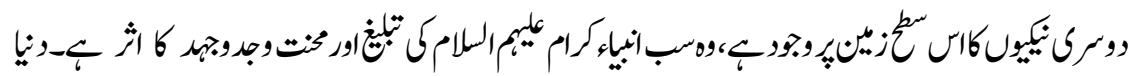

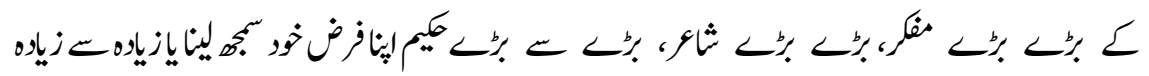

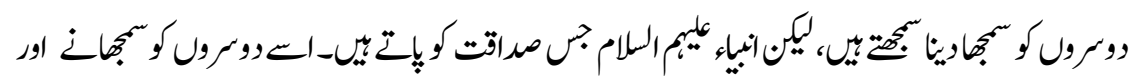

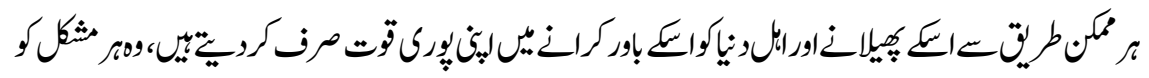

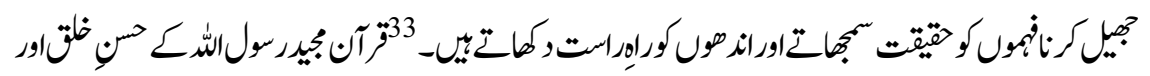

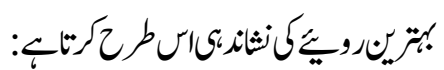

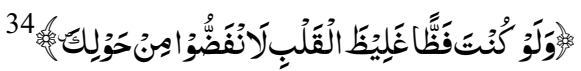

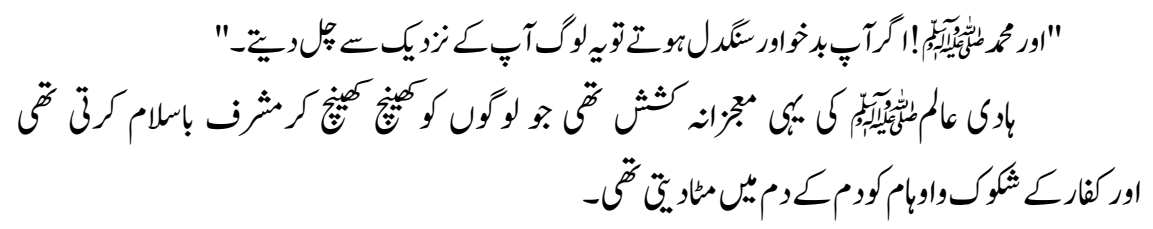

\section{ملاص.كث}

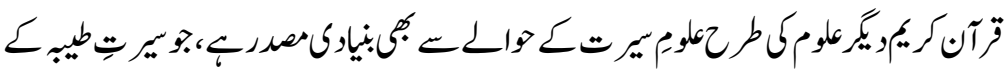

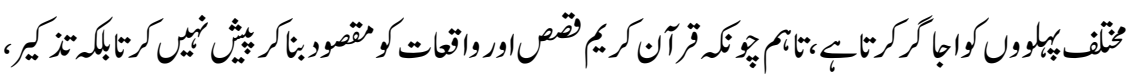

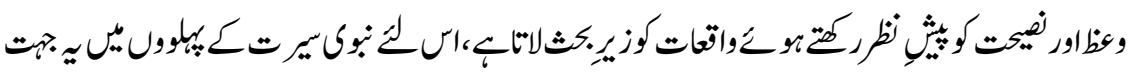

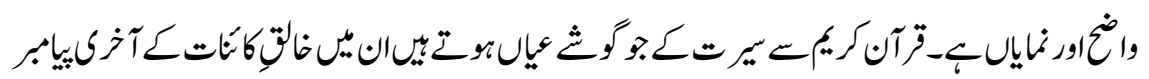

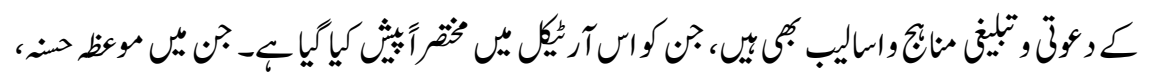

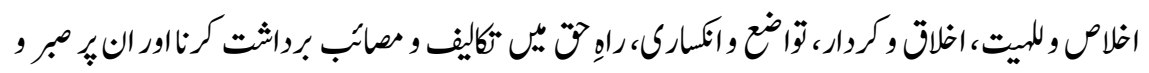

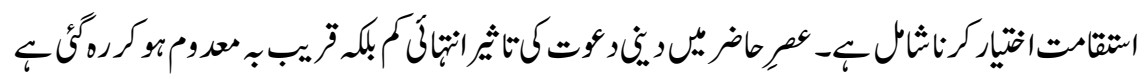

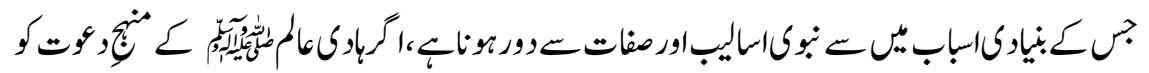

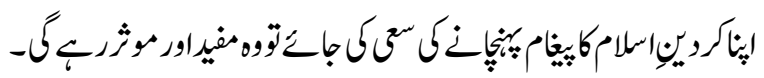




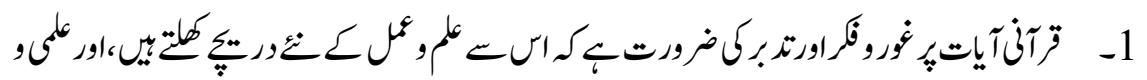

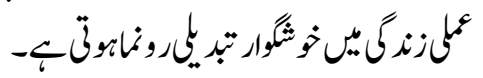

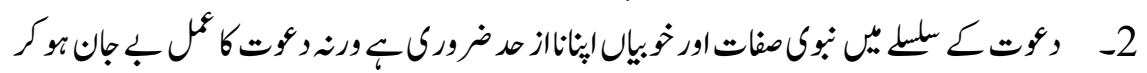

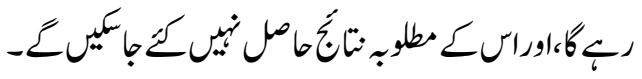

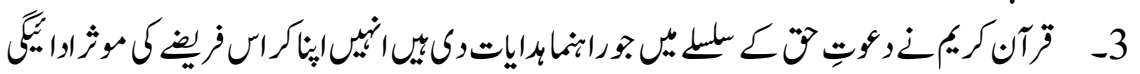

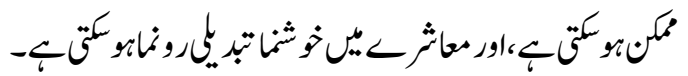

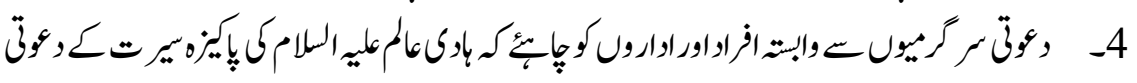

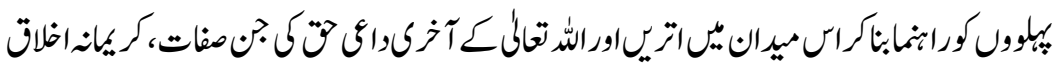

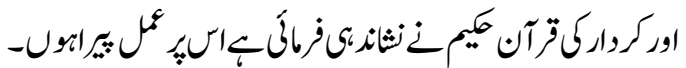

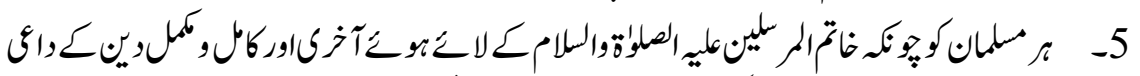

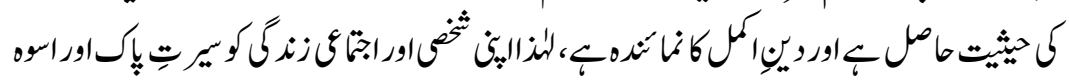

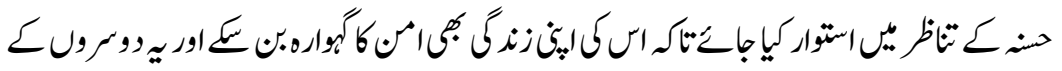

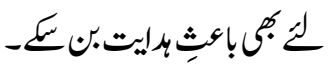

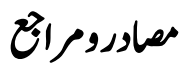

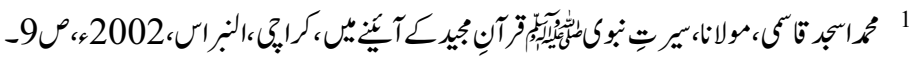
2

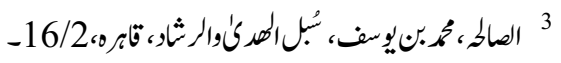

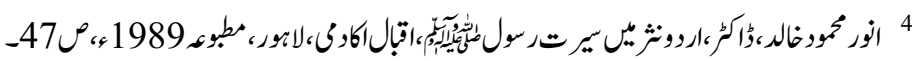

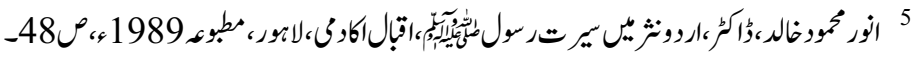
6 أل

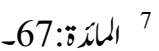
8 9 $-28: \leftarrow^{10}$ 158:-15 


$$
\text { 108:-108 }
$$

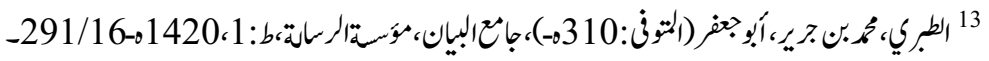

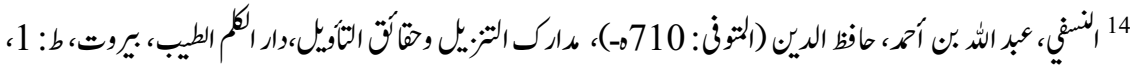

$$
\begin{aligned}
& -138 / 2 \leftrightarrow 1419
\end{aligned}
$$

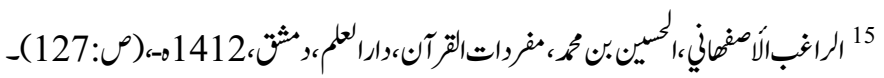

$$
\begin{aligned}
& 16 \\
& 17 \text { الثراء:109- أفري }
\end{aligned}
$$

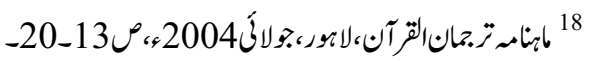

$$
\text { 256:0بر البران }
$$

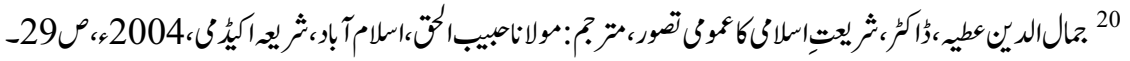

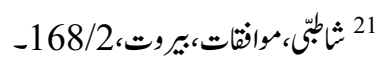

$$
\text { -68:22 الانقام:23 }
$$$$
-44 ، 43: b^{23}
$$

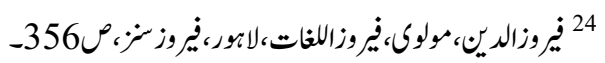

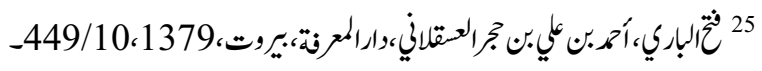

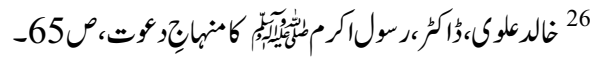

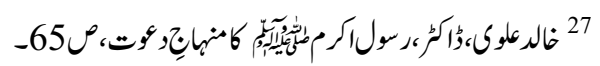

$$
28
$$

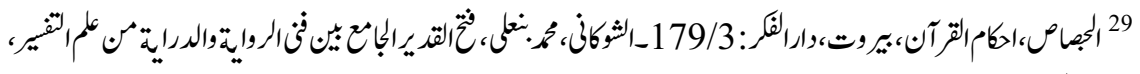

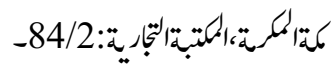

$$
\begin{aligned}
& \text {-90 } \\
& 31 \text { الثرئ:15- } \\
& -112: 32
\end{aligned}
$$

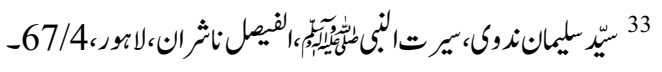

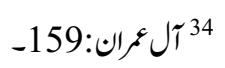

